\title{
Using Crushed Tiles as Coarse Aggregate in Concrete Mix
}

\author{
Wadhah M.Tawfeeq ${ }^{1}$, Maryam AlSaidi ${ }^{2}$, Abdullah Al-Kamzari ${ }^{2}$, \\ Mohammed Al-Shibli ${ }^{2}$, and Zainab Al-Mamari ${ }^{2}$
}

\begin{abstract}
This study investigated the effects of using the crushed tiles (CT) as a coarse aggregate in the concrete mix. The CT is an industrial waste material, and then reuses it in the construction fields will reduce the concrete costs and reduce the environmental pollution. The general properties, such as the specific gravity, water absorption and water content of the natural crushed aggregate and the CT aggregate were tested and compared with natural aggregate. Three different replacement percentages of CT aggregates $(0 \%, 50 \%$ and $100 \%$ ) were used in the concrete mix, in each replacement percentage; W/C and G/S were changed as a parametric study to investigate their effects on slump and compressive strength. In general, the results confirm that increasing the W/C will cause to increase the workability and decrease the compressive strength of the concrete mix that with $\mathrm{CT}$ aggregate. For example, the compressive strength of concrete mix for $100 \%$ replacement of crushed tiles was $28 \mathrm{MPa}$ with W/C $=0.55$ and $\mathrm{G} / \mathrm{S}=1.1$, in comparison with control mix ( $0 \%$ of $\mathrm{CT}$ ) was 38.8 MPa; showed $27.83 \%$ decreasing. While the slump of fresh concrete showed $37.50 \%$ increasing.
\end{abstract}

Keywords - Recycled aggregate, crushed tiles, physical properties, concrete properties.

\section{INTRODUCTION}

One of the significant problems nowadays is the accumulation and management of construction waste. Due to the extensive use of natural aggregate in construction, many countries throughout the world tried to find other of this material to use in construction, such as crushed tiles, pavement blocks, construction waste ...etc. One of the alternatives is to recycle and reuse the waste tile. Crushed tile is an industrial waste that causes environmental pollution. Therefore the possible utilization of this material would reduce environmental pollution. The amount of tile waste on earth is enough for use as an aggregate in concrete. Tile is produced from natural materials sintered at high temperatures. Some parts of tiles are used as flooring and also flooring in tennis courts, walkways, cycling paths and gardens as a ground material. Waste tiles are stored in factory fields because of their economic value. Nevertheless, each year approximately 250,000 tons of tiles are worn out, while 100 million tiles are used for repairs. These waste materials can be recycled to save money [1]. The technology of concrete recycling is well established in the U.S. Recycling of Portland cement concrete, as well as asphaltic concrete, has been shown to be a cost-effective alternative for

Manuscript received July. 8, 2016. This work was supported by Sohar University.

${ }^{1}$ Assistant Professor, Faculty of Engineering, Sohar University, Sohar, PC 311, Oman;

${ }^{2}$ Undergraduate student of Engineering, Sohar University, Sohar, PC 311, new road, street, and highway construction. As early as 1987, more than 1000 lane miles of Portland cement concrete pavement had been recycled into new pavement. Concrete recycling to produce structural grade concrete for non-pavement uses is technically feasible, with certain precautions. For example, it is generally accepted that when natural sand is used, up to $30 \%$ of natural crushed aggregate can be replaced with coarse recycled aggregate without significantly affecting any of the mechanical properties of the concrete [2].

Poon and Chan (2005)[3] presented study on the investigation of blending recycled concrete aggregate and crushed clay brick as aggregates in the production of paving blocks. The results indicated that the incorporation of crushed clay brick reduced the density, compressive strength and tensile strength of the paving blocks. Due to high water absorption of crushed clay brick particles, the water absorption of the resulting paving blocks were higher than that of the paving blocks that did not incorporate crushed clay brick. Although it was found that crushed clay brick impaired the quality of the resulting paving blocks to a certain extent, the paving blocks using $50 \%$ crushed clay brick met the minimum requirements specified by AS/NZS 4455 and ETWB of Hong Kong (Grade B) for pedestrian areas. Also, they found that it was possible to replace $10 \%$ fine RCA by a combination of fine brick and tile aggregate in the production of concrete paving blocks, which showed satisfactory performances.

Fung, (2005)[4] discovered that the maximum content of recycled coarse aggregates could be raised to $50 \%$ from a current practice of $20 \%$ for Grade 30 concrete and below, and to $30 \%$ for Grade 35 to Grade 45 concretes. Lower replacement levels are suggested for recycled aggregates of lower quality. Similarly other properties of recycled aggregate concrete have also found satisfactory and its use in Hong Kong for structural application is now gradually increasing.

Dunster (2007)[5] described the use of both natural stone waste and production waste as coarse aggregates in concrete landscaping products. Many of these concrete products routinely include industrial by products and recycled/secondary aggregates. Example includes mainly recycled concrete aggregates (from crushed production waste), furnace bottom ash, ground granulated blast furnace slag, pulverized fuel ash. Increasingly, manufacturers of landscaping products crush this material into recycled concrete aggregate at the manufacturing site and recycle into new production as a partial replacement for primary aggregates.

Johnny et al (2007)[6] investigated that the salvage of aggregate from the recycled demolition waste is receiving more and more attention across the globe due to its importance in sustaining our environment. 
In this study the waste tiles which already used in Sultanate of Oman were crushed and graded to match the British standard B.S. 882, 1992[7] of grading aggregate. This crushed tiles used as coarse aggregate to mix with natural sand, cement and portal water. The mechanical properties of crushed aggregates were determined and compared to the natural aggregate properties. Different percentages of crushed tiles to replacement the natural coarse aggregate in the concrete mix have been investigated. The effects of this replacement were studied for several concrete mixes that have various $\mathrm{G} / \mathrm{S}$ and $\mathrm{W} / \mathrm{C}$ ratios.

\section{MATERIALS}

\section{A. Fine Aggregate}

Natural sand from AL-Braimi region Sultanate of Oman is used. Figure 1 show the particle size distribution which its grading fits within the limits set out in B.S. 882, 1992 [7]. Also average of three samples was taken to evaluate the bulk specific gravity, water absorption, water content and clay percentage, the values were $2.64,2 \%, 11 \%$ and $2.87 \%$ respectively.

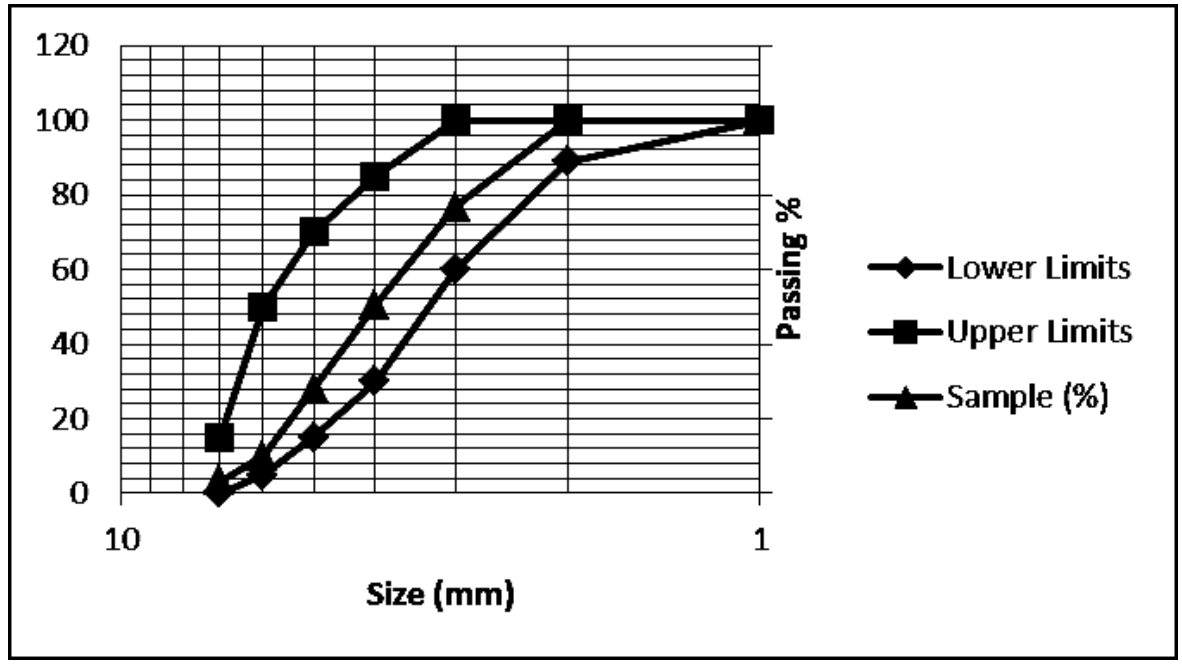

Fig. 1: Particle Size Distribution of Fine Aggregate

\section{B. Coarse Aggregate}

Crushed natural aggregate (gravel) of maximum aggregate size $20 \mathrm{~mm}$ from AL-Braimi region Sultanate of Oman is used. Figure 2 show the particle size distribution which fits within the limits set out in B.S. 882, 1992[7]. Also average of three samples was taken to find each of bulk specific gravity, water absorption and water content, the values were $2.7,1.62 \%$ and $0.66 \%$ respectively.
Waste tiles are obtained from Sohar Tiles factory Sohar, Sultanate of Oman was graded in the laboratory. Figure 3 show the particle size distribution that its grading fits within the limits set out in B.S. 882,1992[7]. The average of three samples was taken to find each of bulk specific gravity, water absorption and water content, the values were $2.435,7.8 \%$ and $0.6 \%$ respectively.

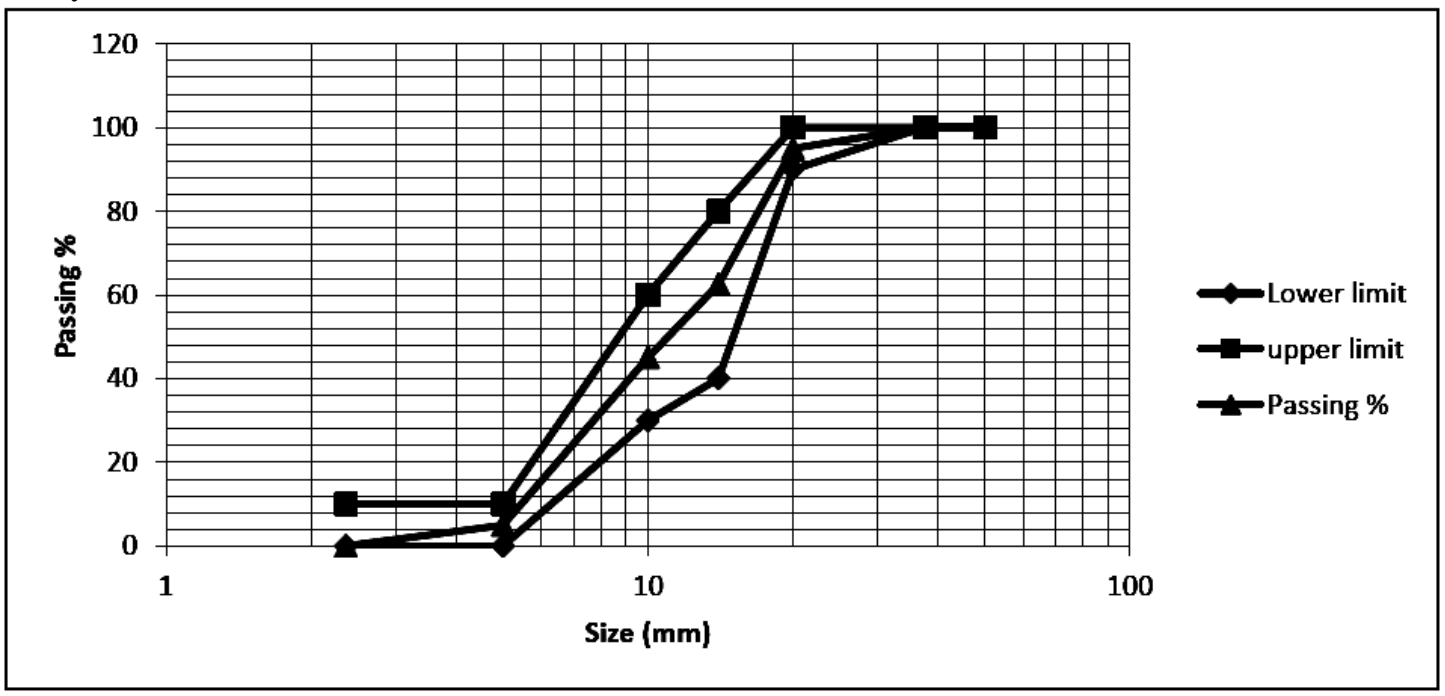

Fig. 2: Particle Size Distribution of Natural Crushed Aggregate 


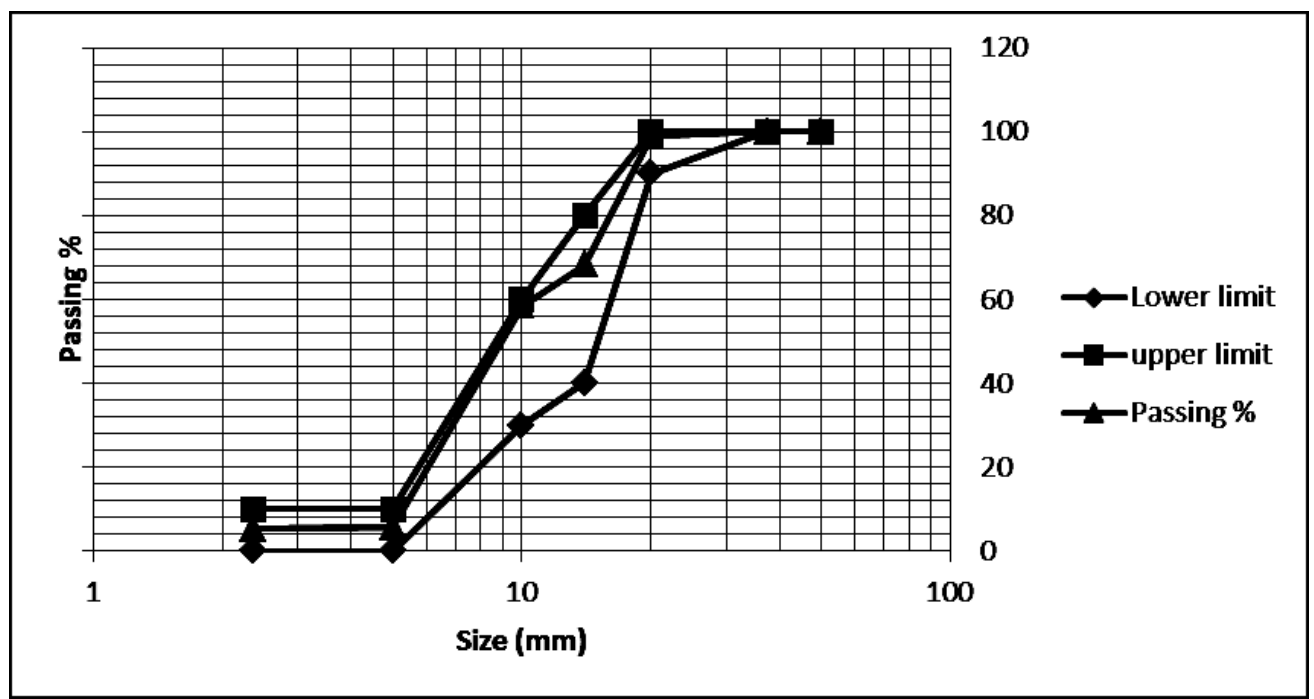

Fig. 3: Particle Size Distribution of Crushed Tiles Aggregate

\section{Cement}

The Cement used in this study is Raysoot-Sultanat of Oman ordinary Portland Cement type (I) according to British Standard Specification BS EN 197-1:2000[8].

\section{Water}

Tap water is used in concrete trial mixes and in curing. Sulfate content, hardness and $\mathrm{PH}$ of water were $250 \mathrm{mg} / \mathrm{l}$, 120-150 ppm, 6.5-8, respectively.

\section{Preparation of SPECIMENS}

In this study, ninety concrete cubes with different mix design were prepared and tested in the concrete laboratory of Sohar University-Sultanate of Oman. Different percentages of crushed tiles aggregates were used with $0 \%, 50 \%$ and $100 \%$ replacement of natural crushed aggregate. Three gravel/sand $(\mathrm{G} / \mathrm{S})$ ratios were used 1, 1.1 and1.2. Also, three different water/cement $(\mathrm{W} / \mathrm{C})$ ratios were used $0.55,0.6$ and 0.65 . The cement quantity for all mixes was constant $400 \mathrm{~kg} / \mathrm{m}^{3}$. The bench marking trial mix was 400:835.2:904.8/0.6. For each trial mix the slump cone test was performed immediately after the mixing to measure workability of concrete.

\section{RESULTS \& DISCUSSIONS}

Compressive strength is the capacity of a material to withstand axially directed pushing forces. While the measurement of the workability of fresh concrete is important in assessing the practicality of compacting mix and also in maintaining consistency throughout the job. Generally, concrete with recycled aggregate has a relatively lower strength than a natural aggregate concrete.

Figure 4 show the slump test results with reference to the $\mathrm{W} / \mathrm{C}$ ratios $(0.55,0.60 \& 0.65)$, for the $\mathrm{G} / \mathrm{S}$ ratio equal to 1.1 with various CT percentage values $(0 \%, 50 \%$ \& 100\%). Meanwhile, Figure 5 presents the effect of CT percentage on the slump values with reference to specific $\mathrm{W} / \mathrm{C}$ values $(0.6)$ when the concrete mixes have different $\mathrm{G} / \mathrm{S}$ ratios $(1.0,1.1 \& 1.2)$.

As it is clear from the figures; the slump of concrete mix was significantly affected by $\mathrm{W} / \mathrm{C}$ ratio and G/S ratio. The slump increased with increasing $\mathrm{W} / \mathrm{C}$ ratio and replacement percentage of recycled crushed tiles aggregate while the slump decreased with increasing $\mathrm{G} / \mathrm{S}$ ratio.

For $\mathrm{G} / \mathrm{S}=1.1 \& \mathrm{~W} / \mathrm{C}=0.6$, Figure 4 shows that the slump for $100 \% \mathrm{CT}$ is higher than $50 \% \mathrm{CT}$ and $0 \% \mathrm{CT}$ by $15.38 \%$ and $25 \%$ respectively. This is mainly due to the surface shape, size difference and replacement percentage of crushed tiles.

Figure 5 shows that, the slump is higher when sand concentration is higher. When G/S is 1.0 the slump is more and then it decreases as G/S is increase. As it is clear the slump is higher with crushed aggregate and lower with natural aggregate. Therefore, various mixing condition such as W/C, grading and volume of recycled aggregates would control the slump of recycled aggregate concrete.

The concrete compressive strength is measured at 7 and 28 days. Figure 6 shows that the compressive strength decreases as crushed tiles replacement percent is increases. Also the optimum compressive strength of 7 days age concrete is achieved when the G/S ratio is 1.1. This is matching the British method to design the trial concrete mix. When $\mathrm{G} / \mathrm{S}=1.1 \&$ $\mathrm{W} / \mathrm{C}=0.6$ difference in strength between the $0 \%$ and $100 \%$ replacement is $28.56 \%$.

Figure 7 shows that the three different mixes having the same trend, they go down as W/C ratio increasing and the strength for the three mixes are maximum when the $\mathrm{W} / \mathrm{C}$ is 0.55 and minimum when the $\mathrm{W} / \mathrm{C}$ is 0.65 . Also the compressive strength decreases as the crushed tiles replacement percent increases. For example, the concrete mix with $\mathrm{G} / \mathrm{S}=1.1$ and $\mathrm{W} / \mathrm{C}=0.65$ the strength was decreased about $18.5 \%$ when $50 \%$ of natural aggregate replaced with $\mathrm{CT}$, then this reduction increased up to $32.27 \%$ when replaced all the natural aggregate with CT $(100 \%$ replacement). 


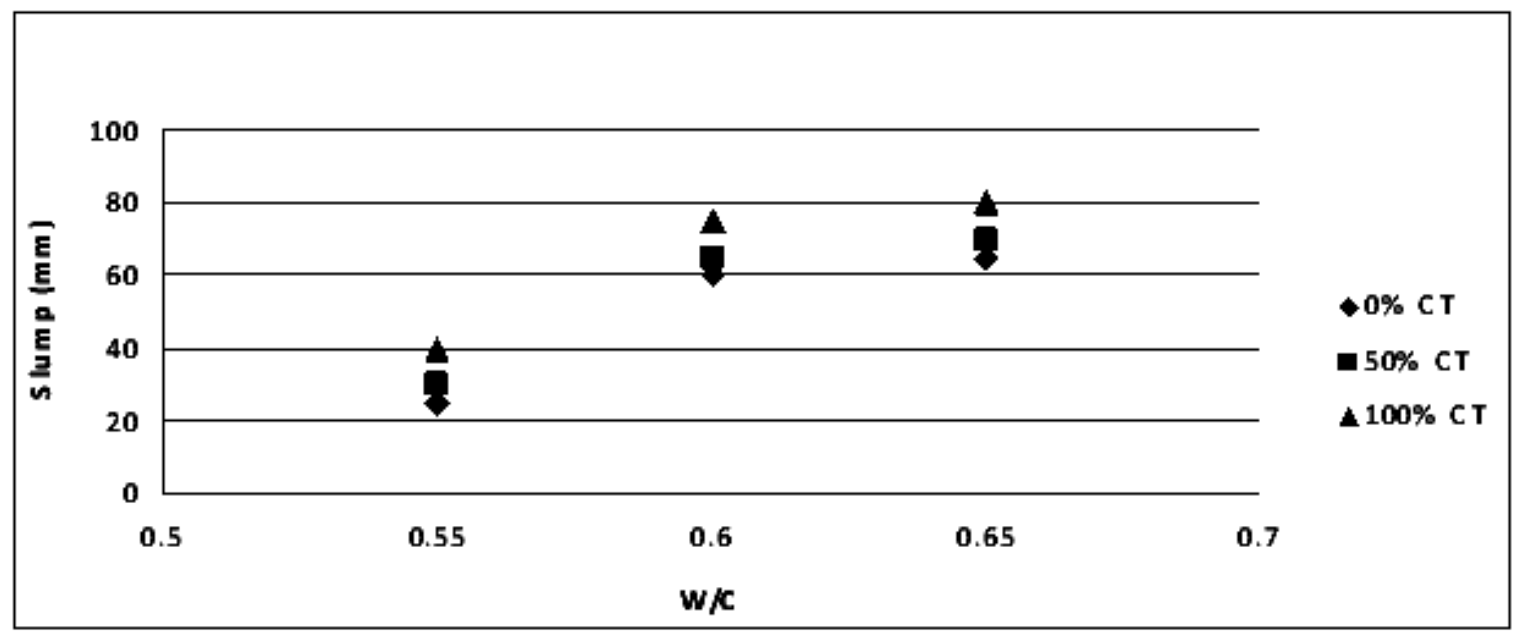

Fig. 4: Slump vs W/C relationships for various $\mathrm{CT} \%$ and $\mathrm{G} / \mathrm{S}=1.1$.

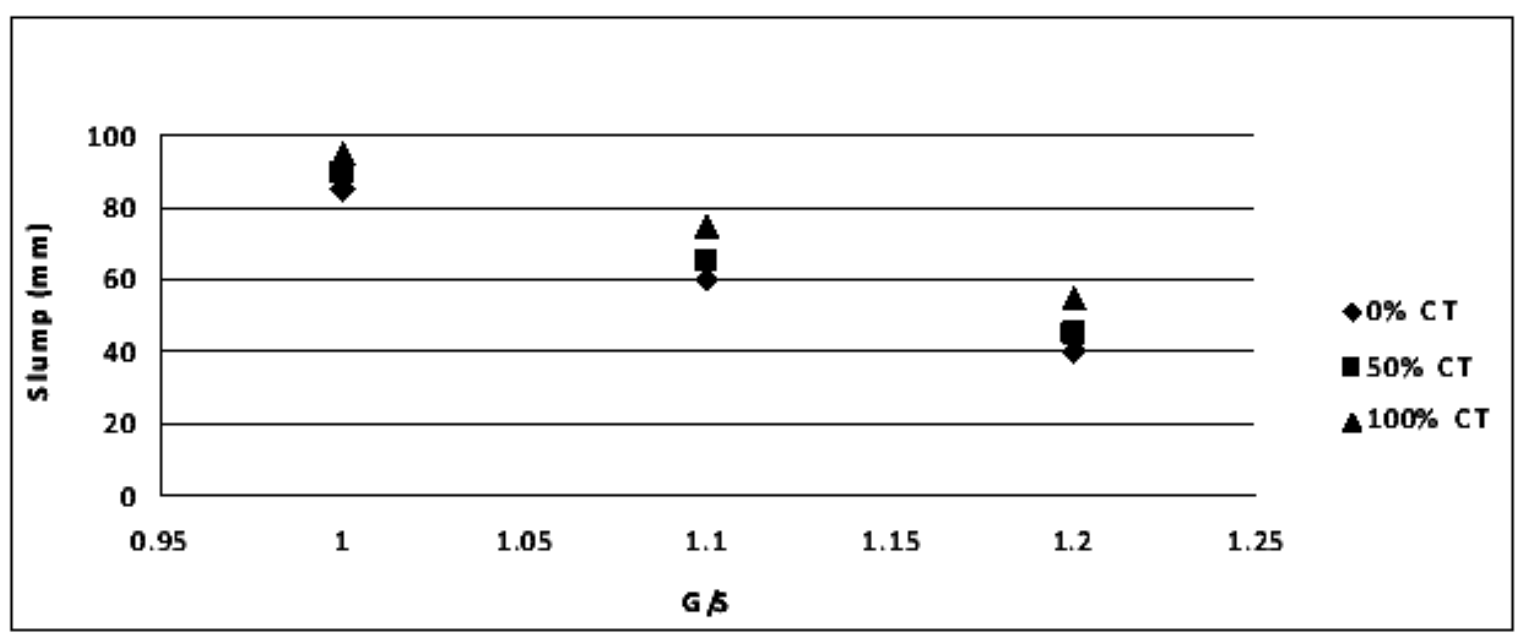

Fig. 5: Slump vs G/S relationships for various $\mathrm{CT} \%$ and $\mathrm{W} / \mathrm{C}=0.6$

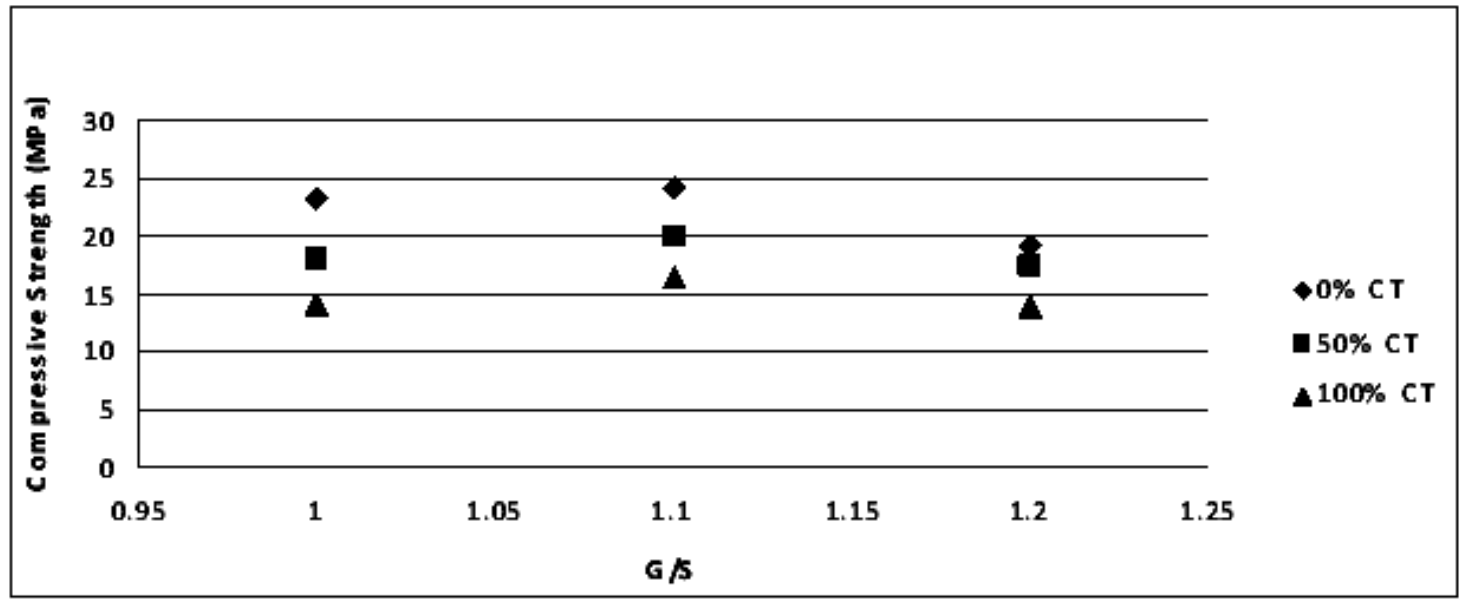

Fig. 6: Seven days Compressive Strength vs $\mathrm{G} / \mathrm{S}$ relationships for various CT\% and W/C=0.6. 


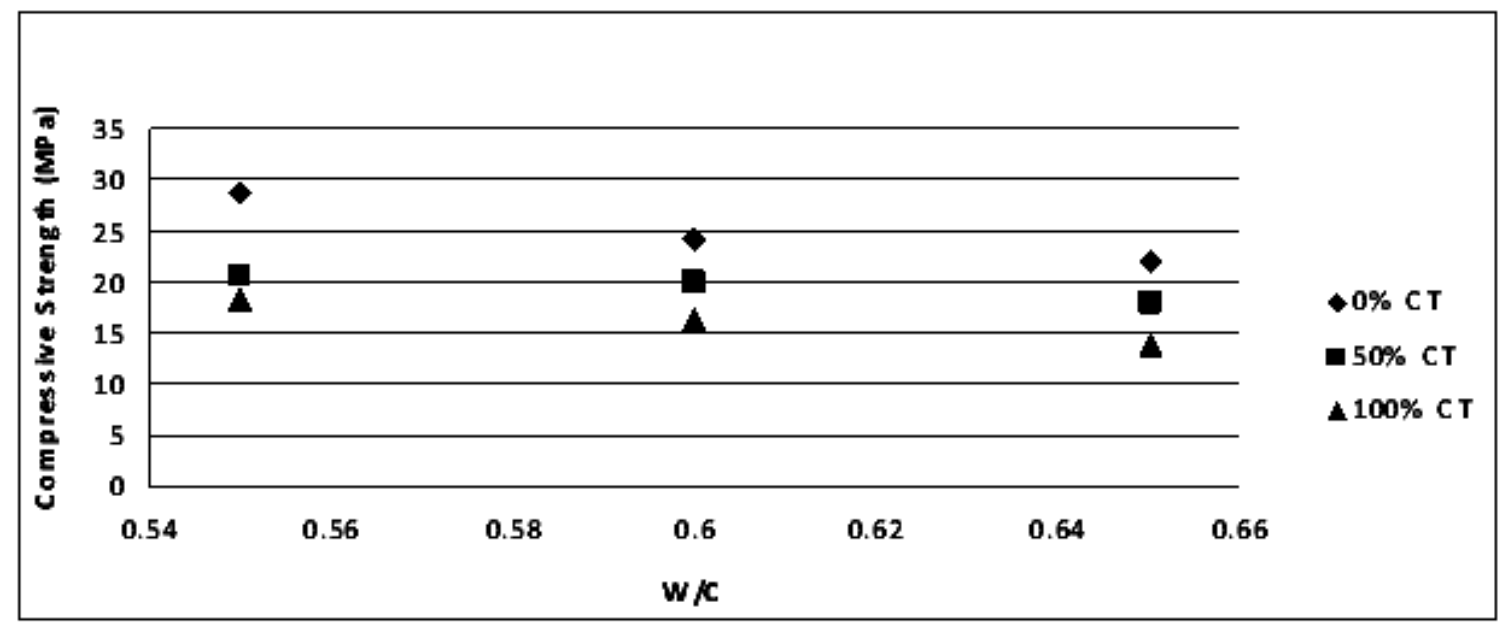

Fig. 7: Seven days Compressive Strength vs W/C relationships for various CT\% and G/S=1.1.

Figure 8 shows that 28 days age compressive strength of concrete decrease as the crushed tiles replacement percent increase. Also same as 7 days compressive strength of concrete the optimum compressive strength can be gotten when the G/S ratio is 1.1. In this study, the benchmark of concrete mix when $\mathrm{G} / \mathrm{S}$ ratio is 1.1 and $\mathrm{W} / \mathrm{C}$ is 0.6 . It is clear that the compressive strength of concrete with $0 \%$ crushed tiles replacement is higher than $50 \%$ and $100 \%$.Overall the compressive strength for both natural and crushed tiles is increased about $45 \%$ at the age of 28 days more than at age of 7 days.

Figure 9 shows a decrease in compressive strength of concrete as $\mathrm{W} / \mathrm{C}$ ratio increase. The highest compressive strength was at $\mathrm{W} / \mathrm{C}=0.55$ and the lowest at $\mathrm{W} / \mathrm{C}=0.65$. For $\mathrm{G} / \mathrm{S}=1.1 \& \mathrm{~W} / \mathrm{C}=0.65$ it was about $17.46 \%$ difference between 0 and $50 \%$ and about $15.77 \%$ between $50 \%$ and $100 \%$ replaced crushed tiles aggregate.

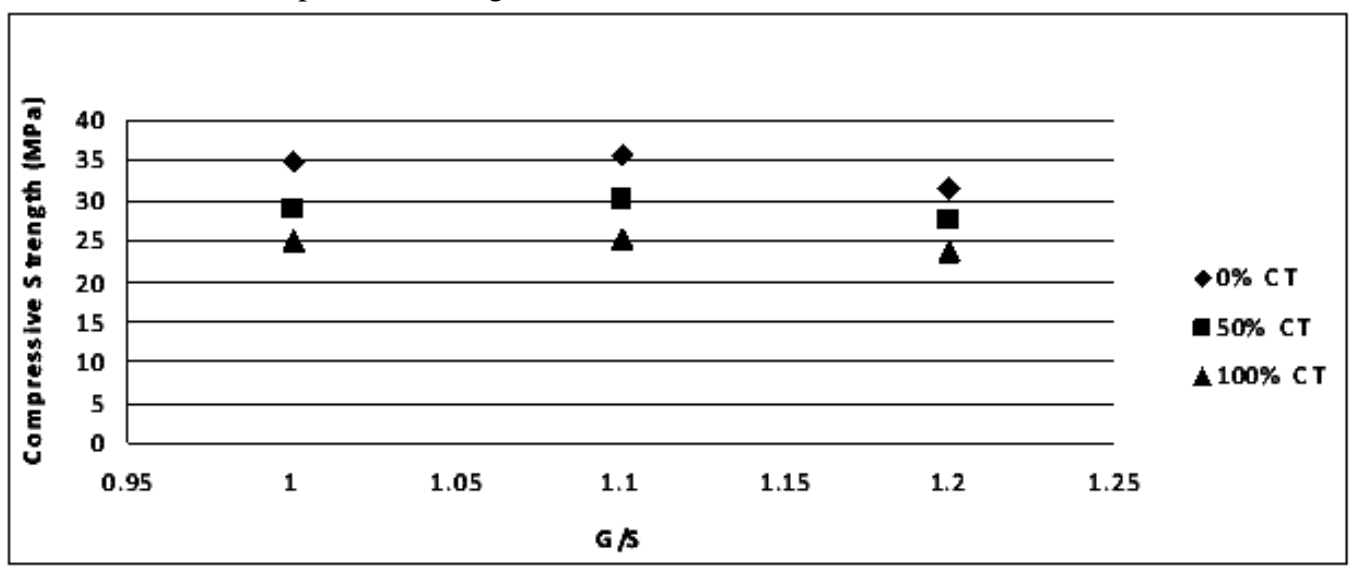

Fig. 8: Twenty Eight Days Compressive Strength vs G/S relationships for various CT\% and for W/C=0.6.

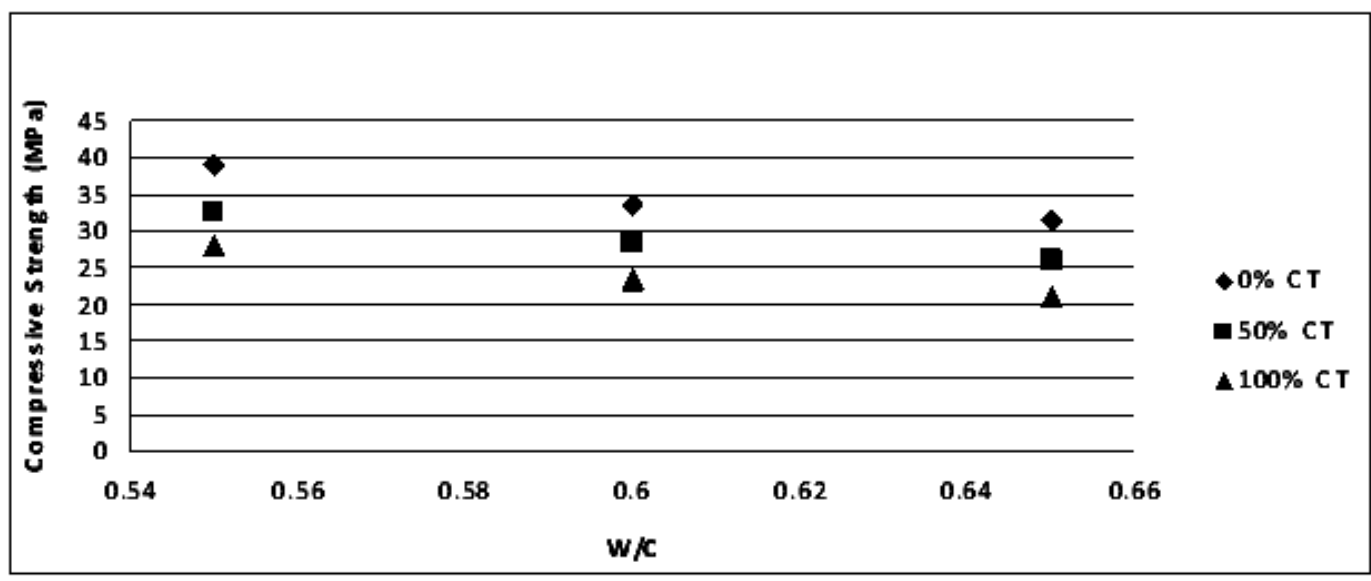

Fig. 9: Twenty Eight Days Compressive Strength vs W/C relationships for various CT\% and for G/S=1.1. 


\section{CONCLUSIONS}

In conclusion, the percentage of replacement and the water absorption of the recycled aggregate in concrete mix change its properties and affect its compressive strength and workability. - The workability of concrete which was investigated through the slump test found affected by the replacement of the crushed tiles aggregate and $\mathrm{W} / \mathrm{C}$ ratio. It was observed that the slump increased by about $8.33 \%$ for the fresh concrete with $\mathrm{W} / \mathrm{C}=0.6$ and $\mathrm{G} / \mathrm{S}=1.1$ when replace $50 \%$ of natural aggregate with crushed tiles aggregate, then this slump increased about $25 \%$ when used $100 \%$ of crushed tiles, compared to the slump value of the concrete without any aggregate replacement ( $0 \%$ of CT). - The compressive strength increases as W/C decreases. The average compressive strength was more than the benchmark (mixes with $\mathrm{G} / \mathrm{S}=1.1 \& \mathrm{~W} / \mathrm{C}=0.6$ ) for mixes with $\mathrm{G} / \mathrm{S}=1.1$ and $\mathrm{W} / \mathrm{C}=0.55$ and it was lower for mixes with $\mathrm{G} / \mathrm{S}=1.1$ and $\mathrm{W} / \mathrm{C}=0.65$. It was observed that the compressive strength decreased by $13 \%$ when the $\mathrm{W} / \mathrm{C}$ increased to 0.65 , on the other hand it increased by $9 \%$ when the W/C decreased to 0.55 .

- In general the remaining compressive strength is about $83 \%$ of the control concrete when the replacement was $50 \%$ crushed tiles and about $72 \%$ of the compressive strength remained when it replaced fully with crushed tiles.

\section{REFERENCES}

[1] I. B. Topcu and M. Canbaz, "Utlization of Crushed Tiles as Aggregate in Concrete", Iranian Journal of Science \& Technology, Transaction B, Engineering, Vol. 31, No. B5, pp561-565.(2007).

[2] Recycling Portland Cement Concrete, DP-47-85. Demonstration Project Program, Federal Highway Administration, Washington, D. C., (1985).

[3] Poon, C. S. and Chan, D., "Paving Blocks Made with Recycled Concrete Aggregate and Crushed Clay Brick", Construction and Building Materials, Volume 20, Issue 8, pp 569-577, October (2006).

[4] Fung, W. K, "The Use of Recycled Concrete in Construction". Doctoral Thesis, The University of Hong Kong (Pokfulam, Hong Kong), HKU Theses Online (HKUTO) http://hub.hku.hk/bib/B30517643. (2005).

[5] Dunster, A M., "Crushed Waste Stone and Production Waste in Concrete Landscaping Products", Case Study, Characterisation of Mineral Wastes, Resources and Processing technologies - Integrated waste management for the production of construction material, October 2007.

[6] http://ascpro0.ascweb.org/archives/cd/2008/paper/CPGT208002008.pdf

[7] BS 882:1992,"Specification for Aggregates from Natural Sources for Concrete".

[8] BS EN 197-1:2000,"Cement. Composition, Specifications and Conformity Criteria for Common Cements". 